\title{
ACADEMIC RESEARCH SUPERVISION: THE UNCONSCIOUS ROLE IDENTITY OF A PhD STUDENT
}

\author{
A-P. Flotman \\ Department of Industrial and Organisational Psychology \\ University of South Africa \\ Pretoria, South Africa \\ https://orcid.org/0000-0001-5663-7279
}

\section{ABSTRACT}

An extensive body of knowledge exists concerning the experiences and personal characteristics of successful PhD students. However, the unconscious role behaviour of the PhD student in an Open Distance and e-Learning (ODeL) academic environment is less well explored. The aim of this article was to study and describe the unconscious role behaviour of a PhD student at a South African ODeL university. Data collection entailed the author reflecting on and writing an essay on his phenomenological $\mathrm{PhD}$ experiences and choosing the most appropriate vignettes for thematic analysis. The findings indicated high levels of free-floating and performance anxieties in the researcher's unconscious existential and phenomenal roles, primarily emanating from conflicting projections and introjections about his competence and perceived incompetence as a $\mathrm{PhD}$ student. The feedback process manifested as a potential space as it became a precious social and psychological environment to hold and contain his transformational anxieties as a student. Practical implications are presented and recommendations suggested to students, supervisors and academic institutions, aimed at enhancing the supervisory relationship in the interest of increased higher degree research outputs.

Key words: anxiety, containment, identity work, potential space, projection, role identity

\section{INTRODUCTION}

South African institutions of higher learning function in a global and national context in which they are being challenged to demonstrate relevance and face increasing pressure to offer value to their respective stakeholders (Council on Higher Education 2016, 20-21; Leibowitz 2017, 95; Swartz et al. 2018, 568). The continuing debate on the purpose of universities (Jansen 2017, 21-25; Swartz et al. 2018, 568) and the national shortage of high-level skills to address, among others, the legacy of inequality in the provision of higher education and to contribute meaningfully to the sustainable growth and development of the country persists (Collini 2017, 56; Marginson 2016, 5-6; Motala, Vally, and Maharaj 2018, 112). To this end, academic and other institutions of higher learning are under unprecedented strain to increase the delivery of master's and doctoral students (Chikte and Chabilall 2016, 58; Pithouse-Morgan et al. 2016, 
225; Sonn 2016, 227; Waghid 2015, 116). However, the main problem has not been solved: postgraduate students struggle to complete their studies at institutions of higher learning and South Africa is faced with low throughput in the entire higher education system (Costa 2019). One of the unintended consequences of this strain is that any latent challenges in the studentsupervisor relationship are brought to the fore. It has been well documented that the studentsupervisor relationship plays a significant role in the successful completion of a research project (Adler and Adler 2005, 15; Halse and Bansel 2012, 378; Kam 1997, 90; Lee 2012, 56-57; Waghid 2015, 112). The nature of the relationship influences both the quality and the timeous completion of the research project (Van Biljon and De Villiers 2013). These studies seem to reveal that the focus of academic research supervision has evolved over the years. In the current discourse about supervision and supervisory practices, the quality of the supervisory relationship appears to have taken centre stage.

\section{Academic research supervision as a relationship}

Academic research supervision has been approached and conceptualised from various perspectives (Halse and Bansel 2012, 379; Maxwell and Smyth 2009, 410; Sonn 2016, 230; Waghid 2015, 87; Yousuf et al. 2019, 336), and is therefore a broad, nuanced construct that is difficult to describe fully. As stated so aptly by Bastalich (2015), with the emergence of convergent and divergent discourses and the subsequent massification of higher degrees, the gaze is firmly on the student-supervisor relationship as the new "problem" to be solved. Recent studies have confirmed that the quality of the relationship between students and their supervisors often determines the progress of the student. For example, successful supervision is associated with the expertise of the supervisors and their willingness to share their knowledge with their students. Nevertheless, supervisors expect their students to work independently (Van Wyk et al. 2015, 27). An article entitled, "Lament of a female postgraduate $\mathrm{PhD}$ student at a South African university" testifies to the centrality of the quality of the supervisory relationship (Magano 2013, 213). In this study, the author describes the journey of a student from having positive self-esteem to a negative, exhausted wreck over an eight-year period. The complexity of the student-supervisor relationship has been highlighted by conceptualising it as the nexus of three interrelated areas: a learning and teaching process, developing the student and producing an acceptable research outcome as a social practice (Todd, Smith and Bannister $2006,165)$. The supervisory relationship is thus framed as a social and reciprocal process. The supervisor remains a critical gatekeeper in holding the ethical, professional and intellectual competence of the student (Campbell 2000, 88), but the student must reciprocate by attempting to be knowledgeable and competent enough to see the process through (Maxwell and Smyth 
$2009,410)$. In a recent review of the literature on academic research supervision, Yousuf et al. $(2019,336)$ found that students always expect supervisors to be knowledgeable, approachable and supportive of their work. Supervisors, on the other hand, expect students to have the necessary research skills, such as autonomy, critical thinking, the ability to locate the topic in the context of the literature and originality. Finally, academic institutions must cultivate a research culture by securing a positive learning environment with commensurable infrastructure to facilitate sustainable, successful research. This indicates that academic research supervision remains a complex educational task, which requires the collective effort of the supervisor, student and the relevant institution to ensure research success (Van Biljon and De Villiers 2013). From the above discussion, academic research supervision could be conceptualised as a dynamic, interpersonal relationship, grounded in mutual respect, to be approached as a learning alliance between student (constantly developing a critical thinking repertoire and evolving as an independent researcher) and supervisor (armed with the requisite research, personal and subject domain expertise). This relationship is supported by multiple stakeholders whose primary task is the successful completion of a higher degree research project (Costa 2019; Lee 2012, 66; Lucey and Rogers 2007, 20; Swartz et al. 2018, 580). Since supervision is also a dynamic relationship with significant unconscious material and influence (Cilliers 2018, 31; Lucey and Rogers 2007, 19; McAlpine and Weiss 2000, 12-14; Tohidian and Rahimian 2019, 16-17), this relationship is studied from a depth psychology perspective in which the systems psychodynamic stance is used as a theoretical container (Long 2018, 156; Petriglieri and Petriglieri 2010, 50; Sievers and Beumer 2005, 67).

\section{Systems psychodynamics}

Systems psychodynamics is rooted in psychoanalysis, object relations, systems theory and the Tavistock Human Institute of Human Relations (Brunning 2014, 259; Fraher 2004, 88). The systems psychodynamic approach has developed into a suitable stance to explore beneath-thesurface behaviour in organisations (Long 2013, 101) and to the study of organisational change dynamics in general (Petriglieri, Petriglieri and Wood 2018, 481). Relevant to this study, systems psychodynamic scholarship highlights the dynamic tension and interaction between the emotions and motivations of members of a given system and the collective norms, rituals and structures of the same social systems (Petriglieri 2020,3). The role identity of the student could therefore also be explained in the context of the larger institutional system and any possible institutional configurations that could stifle both individual and organisational development (Vince 2018, 955). Thus, systems psychodynamics is a body of scholarship underpinned by depth psychology and an interpretive stance aimed at understanding conscious 
and unconscious systemic behaviour (Cilliers 2018, 33). Taking a systems psychodynamic stance is critical to the focus of this study. This theoretical lens explores the unconscious forces that drive the persistence of dysfunctional organisational behaviour (Petriglieri 2020, 4), which has an impact on how students take up their role, manifested through the behaviour and performance outcomes of the student.

\section{Organisational role dynamics}

Anxiety is central to systems psychodynamic theory (De Board 2014, 85) and organisational role dynamics. Furthermore, anxiety is intertwined with the human condition. It is therefore common for individuals to experience anxiety in the face of personal and/or organisational challenges (Obholzer and Roberts 1994, 55). Anxiety is perceived as fear of the future, serving as the impetus or driving force (dynamo) of the relations and relatedness between leaders and their followers (Cilliers and Terblanche 2010, 45). Performance anxiety is prompted when one is haunted by the perception of being incompetent, or unable to perform one's primary task (Hoggett 2013, 71). Survival anxiety is triggered by the unpleasant realisation that one has to change in order to survive physically and emotionally. Free-floating anxiety is not linked to a specific object (Long 2006, 45-48). Anxiety can also be characterised as paranoid (when one feels threatened) and persecutory (when one feels victimised) (Sievers 2009, 101). Individuals are compelled to defend themselves against these anxieties as a form of containment and to retain control (Sievers 2009, 101-102). Thus, where there is anxiety, one is likely to find defensive mechanisms and behaviour. According to Long (2008), defences may include a range including perverse, for example when reality is denied; psychotic, which is characterised by splitting, projection and projective identification; neurotic, for example, when there is repression, regression and transference; or realistic, when there is a real sense of danger, both physically or emotionally.

"Role" denotes the description of what needs to be done (Long 2018, 163) or a way of adaptation, for example, to authority, structure and responsibilities (Czander 1993, 66). Incongruence between the person and the role often leads to role stress or anxiety (Czander 1993, 67). Furthermore, a role has three constitutive elements (Obholzer and Roberts 1994, 56). The normative element reflects the conscious, rational and measurable tasks of the role to be fulfilled, often found in an employee's job description. The existential element contains the lived, experienced, unconscious internalisations (incorporations) of external values, attitudes, beliefs and feelings, which then manifest in behaviour. Finally, the phenomenal element reflects the projections/projective identifications either made onto the other or received from the other. Projection involves ejecting parts of oneself onto others and distancing from these, while 
projective identification is the interactive process of unconsciously identifying with projected feelings or material (Halton 2003, 152). When perpetual projections are internalised by the projectee, the sense of identity of that person becomes affected (Campbell and Groenbaek 2006, 121). Projective identification results in "feeling at one" with the object of projection to control the reaction and behaviour of such a person or object (Vince 2018,955). Introjection is a process of internalisation of bad/good parts from others to alleviate anxiety by creating congruency (De Board 2014, 86; Obholzer and Roberts 1994, 57). A related projective process is transference, which involves the displacement of past wishes and feelings onto people in the present (Long 2013, 154). During counter-transference, other people's feelings and emotions are experienced as one's own (Halton 2003, 153). Relevant to this study, these projective processes manifest as the role is taken up consciously and unconsciously with varying degrees of complexity in a given organisational system.

Role identity, on the other hand, reflects the unique, conscious and unconscious manner in which one's organisational role is taken up (Campbell and Groenbaek 2006, 122; Petriglieri $2020,5)$. Identity will manifest in how the primary task is managed through on-task, off-task or anti-task behaviour (Hoggett 2013, 69), how different boundaries are managed (De Board 2014, 86), to what extent both the self and others are authorised (Long 2018, 164; Nagel 2020, 79) and how anxieties are contained in the interest of creative thinking in pursuit of the primary task (Sievers 2009, 102; Vince 2018, 960). The uniqueness in how the role is taken up will make the system similar to others, but also unique (Campbell and Groenbaek 2006, 99).

An extensive body of knowledge exists concerning the experiences and personal characteristics of successful PhD students (Adler and Adler 2005, 13-14; Govender and Ramroop 2013, 102; Halse and Bansel 2012, 390; Marcketti, Mhango and Gregoire 2006). Related studies include the exploration of the power of the unconscious in doctoral supervisor relationships (Lucey and Rogers 2007, 18), the exploration of supervisory experiences through metaphors (relating to both conscious and unconscious elements) (Van Laren et al. 2014) and the psychological coping mechanisms of both student and supervisor during the research journey (Gordon 2003, 183). These studies have made invaluable contributions to the study of some of the dynamic forces at play in the student-supervisor relationship. However, the unconscious role behaviour of $\mathrm{PhD}$ students has been less well explored, particularly in an Open Distance and e-Learning (ODeL) academic environment.

\section{Research purpose aim and contribution}

The purpose of this study was to expand students' and supervisors' understanding of the role identity of students in the supervisor-student relationship. Consequently, the aim of the research 
was to study and describe the systems' psychodynamic role identity of a $\mathrm{PhD}$ student at a South African university. The primary contribution of this study lies in the explication of how the student consciously and unconsciously assumes the systemic role and how this enhanced understanding could authorise the student, supervisor and organisational system as mutually impacting entities.

\section{RESEARCH METHODOLOGY}

\section{Research approach and setting}

The research was qualitative, explorative and descriptive in nature to describe the lived experiences of the researcher. The design of the study, which was guided by the hermeneutic phenomenological stance, allowed for the elucidation of real-life experiences and in-depth description (Clarke and Hoggett 2009, 44; Sievers 2009, 103) of the conscious and unconscious role behaviour of the researcher. The $\mathrm{PhD}$ in Industrial and Organisational Psychology being offered at a tertiary ODeL institution in South Africa constituted the setting for this research. The first year of the programme entails the successful defence of a research proposal. A successful defence leads to the continuation of the study from the second year until the eventual completion of the degree. The journey is characterised by independent research by the student and continuous interaction between the student and the supervisor. The ODeL environment is characterised by relevant distance education pedagogies and the latest online learning methodologies to enable multiple forms of dialogue and interaction that can bridge the distance between lecturers and learners in a given, ever changing socio-political and economic context (Arinto 2016; Garrison 2009, 94-95).

\section{Data collection and procedure}

The researcher utilised an auto-ethnographic design (O'Hara 2018, 15) informed by the hermeneutic phenomenological paradigm (Van Manen 2014, 88; Victor and Barnard 2016). Data collection entailed that the author had to write a comprehensive essay (journalling) on his experiences as a $\mathrm{PhD}$ student over a three-year period. The most appropriate vignettes were then selected for analysis, guided by the research question and aim of the study. Ethical clearance for the study was obtained from the participating university, with reference number 2015/CEMS/IOP/040.

\section{Data analysis and interpretation}

Data analysis consisted of systems psychodynamic role analysis (Alvesson and Skoldberg 
2010, 115) and thematic analysis (Braun and Clarke 2006, 80-82) to develop themes. An inductive and open-coding approach was used. The researcher then cross-validated the emergent themes according to the process suggested by Maclaran and Catterall (2002). Data were interpreted by using the systems psychodynamic lens (double and triple hermeneutics) (Clarke and Hoggett 2009, 45; Petriglieri 2020, 5). Findings are reported by adopting a qualitative reporting style.

\section{FINDINGS}

The emerging themes of the study are as follows: envelopment in existential and phenomenal role dynamics, taking ownership through self-authorisation and feedback as potential space.

\section{Envelopment in existential and phenomenal role dynamics}

The following vignette taken from a journal reflection illustrates the persistent tension between introjections of having the perceived competence and confidence versus the consistent presence of an inner voice questioning my competence.

"With my academic background, I should be and want to be an excellent, exemplary student. One that my promoters would be proud of. But, do I have the 'academic gravitas' (as often described by one of my promoters) and resilience required to successfully complete this research project?"

In hindsight, these conflicting introjections created anticipatory and performance anxiety related to whether I had the requisite skill set in the context of an arduous research journey into the unknown. It also triggered succession anxiety in the archetype child following the promoter as parent. What amplified my performance anxiety was the fantasy that I should be able to balance my personal life, academic workload and my social life perfectly with my study commitments. When I was unable to meet this expectation, which was an impossible task, the inevitable emotional response was guilt and disgust. The desire for a more prescriptive approach by my supervisors, in terms of time boundaries, did not alleviate my anxiety. In fact, it created even more performance anxiety. Questions such as, "What is the due date?", "When do you expect chapter 3?", were often followed by a rebellious child response: "Why must I decide when to submit?" The open-ended, flexible stance of my supervisors in terms of time commitments created more anxiety for me. I needed some structure and even instructions (basic assumption dependence) to help contain my free-floating anxiety. The feeling of being overwhelmed, coupled with the desire for a more instructional approach, reminded me of my high school experiences and transported me back into the past. There was, therefore, a definitive impact of unconscious past experiences in the form of projective processes, such as transference 
and a defensive response to my anxiety in the form of regression. There are other examples of my efforts to contain my performance anxiety, such as wanting one of my supervisors to do the data collection on my behalf by facilitating a listening post - in effect attempting to "outsource" my data collection phase (basic assumption dependence) or continuously referring to the study as "our research". This basic assumption behaviour (we-ness) was perhaps also a defence against the work that I had to own and for which I had to take accountability.

Another observation manifested in the form of perceived positive projections of competence from my supervisors, academic colleagues and friends. I could experience authorisation from my supervisors, often in the form of the respectful way requests were made and feedback provided, the way in which we interacted with each other and perhaps even unconscious messages being delivered through the nature of the supervisory relationship. Related to these projections were the representations of my supervisors as the internalised good parent. Authorisation also came in the form of being "congratulated on my progress" and being reminded by colleagues that I was "already a senior academic in the department and [would] continue to be an excellent $\mathrm{PhD}$ student". However, this form of authorisation created performance expectations, which in turn created more performance anxiety. Authorisation that resulted in performance anxiety was experienced as a rare or uncommon phenomenon. Perhaps this was not "authentic" authorisation, but seduction dressed up as authorisation, because it had created representations in my mind of objects not to be trusted (Czander 1993, 98). Authorisation from the side also came from colleagues who requested me to join a $\mathrm{PhD}$ student group. The invitation was to share some of my $\mathrm{PhD}$ student experiences and "best practices"survival tips - with them. Even in this case, the perceived authorisation came with an experienced burden, which was to complete my studies as quickly as possible to prove that my "best practices" were indeed useful to other students. Perhaps this dressed up form of authorisation was another form of seduction, and therefore not real authorisation. The fact that I had two supervisors also resulted in projections of perceived corruption. Access to two experienced supervisors caused envy and jealousy. The prevailing narrative was that I was being "advantaged by the system". I also experienced conflicting projections when friends and colleagues would ask: "When are you going to finish?" or "Are you still busy with that PhD?"

\section{Taking ownership through self-authorisation}

The following vignette, which was also taken from a bullet under lessons learnt in my reflective journal, illustrates that at some point in the research journey, the student has to take ownership of the project consciously. Student and supervisor often "think together", reminiscent of a tango. However, the handing over of the research baton, so to speak, is facilitated by the attitude 
of the supervisor (letting go) and the taking of ownership by the student (taking up/on). In my case, it happened when a question arose regarding the nature and design of my research. The question was posed:

- Is this a descriptive, exploratory or explanatory study?

During this conversation, it appeared that there was a difference of opinion. I suggested that I should review the literature and return with a theoretically grounded argument regarding the type of research to be undertaken. This was the kairos moment in my study, which set the tone for the rest of the research project. I sensed a significant shift from dependency on my supervisors to interdependency, from deauthorisation of the self to self-authorisation and from disowning my research project to taking ownership of it. I had come to the realisation that ownership is critical to the entire research process. Justification is at the core of rigour and trustworthiness. Ownership includes decision-making and sound decision-making implies the ability to justify each action taken on the research journey. This kind of research transparency is facilitated by the conscious act of taking ownership. Perhaps one of the indirect spin-offs of taking ownership through self-authorisation practices is that it allows students as emerging researchers to find their own voice or identity. What also nurtures the supervisory relationship is an awareness of one's role (identity). "In this relationship, and in this context, I am the student, not the academic colleague, and they are my promoters" and, "I always have to honour my primary task commitments". Thus, by being aware of one's role, primary tasks and where the boundaries are, a more mature role identity is created.

\section{Feedback as potential space}

The quality of the supervision relationship is often tested in the furnace of the feedback process. Most people "fear" feedback, because it is often equated with "criticism" and the recipients also regress to past experiences. The supervisory relationship is nurtured through the quality of the feedback process. However, there was a time when the supervisory relationship was tested. One of my reflections in my journal testifies to this experience:

"Today was tough, rough, deeply disappointing! I expected my promoters to say, 'we are happy with the quality of the manuscript, please submit for language editing'. These words were not uttered today. In fact, it was said, 'there are aspects of the study that still need to evolve to the next level of abstraction'. I feel devastated. How am I going to pick myself up again? What on earth does this mean - 'evolution', 'higher level of abstraction'? Okay, I know what it means, but do I really want to do it? I thought that like an aircraft, I was coming in for the landing, however, I was asked to almost hysterically, 'retract the landing gear, retract the landing gear ...!"” 
I walked around like a zombie for a few days. My family and others in close relationships were primarily on the receiving end of my anger, disgust and disappointment. It took a while to return to the research project, because both difficult emotions and disjointed thoughts had to be processed. My representation of my supervisors as nagging, demanding and unreasonable parents created frustration with the process, doubt in my ability to complete the project and despair about ever being able to complete the research study. In hindsight, the manuscript was not ready and had to evolve. The feedback had added significant value to the final product. Despite the emotional turmoil, in the end, I always felt safe and contained. I felt that the feedback process was authentic; that I was being held by my supervisors, the supervisory process and the supervisory relationship.

Furthermore, feedback sessions were always set up by my supervisors like an event, like a ritual, perhaps to contain their anxiety. There was always clarity about the task boundary (both social and academic), the space boundary and the almost unspoken ego and organisational boundaries. Despite these firm boundary conditions, there was always lingering anticipatory and performance anxiety. There was always the expectation of new demands to be issued, the verdict of inadequate work and more submissions to follow. As the research journey unfolded, the quality of the supervisory conditions described above enabled me to judge less, defend less and shift by embracing the authenticity of the feedback process. This process unlocked the potential of the feedback to enhance my research (potential space) provided by my supervisors. The positive spinoff when feedback is approached as potential space, as opposed to punishment, is that it inevitably adds immense value to the research process.

\section{DISCUSSION}

The aim of this research was to study and describe the unconscious role identity of a $\mathrm{PhD}$ student at a South African ODeL university. It is evident that I experienced high levels of anticipatory, free-floating and performance anxieties in my existential and phenomenal role as a student (Obholzer and Roberts 1994, 122; Petriglieri 2020, 6). Conflicting introjections between projected competence and perceived incompetence (doubts and questions regarding my competence) led to more performance anxiety. I defended myself against these anxieties by depending on my supervisors in the form of competent, good objects (Klein 1997, 123), longed for more structure and a more prescriptive supervisory approach (to contain my anxiety) and idealised my supervisors. This idealisation, which could have emanated from my own envy of them (Nagel 2020,88), manifested in my behaviour of wanting to emulate them and not wanting to disappoint them. However, whenever I failed in my expectations, I experienced distress, guilt 
and shame (May 2018, 140). In the interest of my own psychological coping, I had to embrace my supervisors as loving, kind, reassuring and understanding parents (Fowlie and Sills 2011, 55). Furthermore, in terms of basic assumption behaviour, "we-ness" manifested in an attempt to share the burden and anxieties of the research project with my supervisors.

I also projected competence onto my supervisors and incompetence when I did not agree with their feedback, or when I believed my perception that my progress was being deliberately delayed. Free-floating and performance anxieties also manifested in off-task behaviour, for example searching for references when difficult feedback had to be processed. However, empowerment notably came in the form of containment (Fraher 2004, 23) through the unconscious task of the supervisor to hold potential space for the student, which in this case had a positive impact on the supervisory relationship, as well as authorisation (Madurai 2017, 108) from above (supervisors and university managers), from the side (colleagues and peers) and from within (myself as researcher). These findings seem similar to previous studies (Gordon 2003, 183; Lucey and Rogers 2007, 17; Van Laren et al. 2014) in terms of how perceived and experienced power dynamics, particularly unconscious power dynamics, have an impact on the supervisor-student relationship, and the reality of student projections described by Akala and Backhouse (2015). The findings also allude to the identity work of graduate students as reported by Adler and Adler $(2005,15)$.

The taking of ownership through self-authorisation seems to be a useful observation in the context of this research project. Ownership is undermined when the supervisor finds it difficult to let go of the research. It has been reported that supervisors often overidentify with the research or personalise the supervision role to such an extent that the research outcome is interpreted as a personal success or a personal failure (Cilliers 2018,41), thus making it difficult for the student to own the study. Related to this dynamic of struggling to let go of the project is the student getting caught up in the basic assumption behaviour of dependency (Fraher 2004, 24). Student and supervisor could also collude (Hoggett 2013, 70) because both would be benefiting from this psychological arrangement - the supervisor is "doing the work, with subsequent accolades for having delivered yet another successful student" and the student "benefits from the successful outcome" of this process. The supervisor could become so engrossed in the project that the student feels that it is no longer his or her research. What allows for the taking of ownership is a shift from dependency to interdependency (Hollway 2013), the deliberate assumption of accountability and equipping oneself with the requisite skill set to be able to do the hard work that is required (Nagel 2020, 122).

This taking of ownership seems to be related to some form of identity work (Barnard and Flotman 2020, 5501) to be done by the student. The taking up of a new role as a student in the 
supervisory relationship entails a psychosocial dynamic where the student as a person and the formal role intersect (Sievers and Beumer 2006, 67) in the supervision context. Identity work involves cognitive, emotional and social processes that are social and systemic in nature (Kreiner, Hollensbe and Sheep 2006, 1033; Snow and Anderson 1987, 1338). This difficult, yet important identity work is often stimulated by anxiety (Alvesson and Wilmott 2002, 623). Identity work is both conscious and unconscious and entails the negotiation of personal needs, aspirations, beliefs and expectations when adjusting to latent role demands, which find expression in projective processes to be worked with by the student and the supervisor (which is beyond the scope of this study) (Petriglieri and Petriglieri 2010, 44).

Feedback has always been a critical dimension in the student-supervisor relationship (Van Biljon and De Villiers 2013). Feedback is often perceived as a painful experience. However, this unpleasant experience can be cushioned by good enough containment through an adequate holding environment (Clarke, Hahn and Hoggett 2008, 86). The supervisory relationship is characterised by an unspoken expectation of the students that the supervisor will "hold" them, that is, soothe their discomfort and facilitate their meaning and sensemaking (Petriglieri and Petriglieri 2010,60). This is particularly important during the feedback process. Holding and a holding environment refer to a social and emotional space that reduces distress and facilitates sensemaking (Petriglieri and Petriglieri 2010, 51). Psychodynamically, "space" describes "an intermediate area of experiencing, to which inner reality and external life both contribute" (Winnicott 1975, 230). Potential space is a relational and psychological space, which is accessed by adopting a particular way of being, in relation to the "other" (Jemstedt 2000, 127). Feedback has this inherent potential when combined with good enough containment, thus resulting in safe enough potential spaces.

The study has a number of implications, which can be framed as follows: the supervisory relationship is a dynamic, systemic, emotional container. I therefore advocate the inclusion of a psychodynamic dimension in the training of supervisors to raise awareness of the appreciation of unconscious material in the supervision relationship. Because the research project is an anxiety-provoking journey, supervisors will understand the importance of creating an adequate holding environment (Clarke et al. 2008, 124), in particular for the transformational anxieties of the student. In doing so, supervisors will be reminded of their unconscious task, which is to hold potential space for the student. Another dynamic in the context of the low higher degree throughput discourse is that students, through projective identification, could experience the collective performance and survival anxieties of the university as a system (Cilliers 2018, 44), that emanates from increasing concern about the financial sustainability of institutions of higher learning. This study also has implications for the well-being and psychological coping of 
academic research supervisors. In a recent study by Cilliers (2018), strong reference is made to the intense anxiety of academic research supervisors in their phenomenal role by containing a primary task that ostensibly does not belong to them. The subsequent sustained attack on academic supervisors (Chikte and Chabilall 2016; Emilsson and Johnsson 2007, 165; Govender and Ramroop 2013) does not bode well for their well-being and the critical role they have to play in the student-supervisor relationship. What happens to the student as an object when academic supervisors experience themselves as persecutory objects? This is significant because reality gets distorted when, for example, the student is represented (unconsciously) as a spoilt, rebellious brat and the supervisor is represented (unconsciously) as an unfair, demanding parent. A final implication is the identity work students must perform in the new relationship. Students struggle to cope with tensions in the self (Kreiner et al. 2006, 1034) as they take up the role as student (i.e., "In this context, I am the student and not the HR director of Company X"). Being mindful of the limitations of this study, it is intriguing to see how little research on student role identity has been done, to determine whether the role identity of students plays an important role in the student-supervisor relationship, how the student role is taken up and the impact it has on the research project.

\section{CONCLUSION}

My role identity manifested in how I consciously and unconsciously took up the role as a $\mathrm{PhD}$ student at an ODeL institution. In my normative, conscious role, I was always clear about my role as a $\mathrm{PhD}$ student to complete my research project successfully according to specific guidelines, under the supervision of my supervisors. However, my unconscious experiences (existential and phenomenal roles) were characterised by free-floating and performance anxieties, primarily emanating from conflicting projections and introjections about my competence and perceived incompetence as a PhD student. The primary task was generally characterised by on-task behaviour, but also off-task and anti-task behaviour as defence against the cognitive and emotional work to be done. Despite these anxieties, which gradually subsided because of more conscious on-task behaviours, I increasingly felt safe and contained and rarely experienced shame or unbearable vulnerability. Perhaps this is what also enabled (authorised) me to do the work (primary task) as a PhD student. Furthermore, I experienced authorisation from above, from the side, but importantly, also from within (self-authorisation). In the context of enablement, the feedback process manifested as a potential space because it became a precious social and psychological environment to contain my transformational anxieties as a student. Innovative reflective spaces are therefore critical to role transition. In creating these spaces, supervisors will be able to nurture suitable holding environments, among others, for 
enabling students to do essential emotional and unconscious identity work as they take up the role of student in a dynamic systemic environment. It can be hypothesised that role identity awareness facilitates self-authorisation, potential space and flow. However, the absence of adequate role identity awareness creates dependence, deauthorisation and inflexibility. The low throughput rate of students has become a permanent discourse in the corridors of institutions of higher learning. I suggest that one of the reasons for this low throughput rate is that students and supervisors are stuck in the above-mentioned unconscious, object relations drama.

\section{LIMITATIONS}

The findings of this study are based on one student's experiences in an ODeL environment. The study therefore has limitations in terms of its application to other student experiences and in different institutional settings. However, from a qualitative research stance, it is up to individual readers to assess the trustworthiness of the study and the extent to which they can identify with the experiences of the researcher and the findings of the study (Churchill 2018, 207). Inherent in ethnographic and other phenomenological reflections is the researcher's subjective experiences, understandings and interpretations (Crowther, Smythe, and Spence 2015, 453). This study presents a singular account which may or may not resonate with other students in similar educational and research contexts. However, the researcher adhered to the systems psychodynamic stance, which is clear about the framework and processes to be followed. In doing this, the researcher will be able to remain in the role as researcher of the study.

\section{RECOMMENDATIONS}

To address the broader application of the study, it is recommended that more research on student role identity with a larger sample size and a longitudinal design at different institutions of higher learning be conducted. If more explicit role identity work has to be done by students, academic research supervisors will have to be enabled to take up this role through appropriate supervisory training. This kind of training will assist supervisors to 1) play a more facilitative role to help students with identity work, and 2) hold potential space for the student in the context of an anxiety-provoking research journey.

Academic research supervisors often complain about their workload, their psychological well-being and becoming the scapegoat for the inadequacies of the larger institutional system. These existential and phenomenal role experiences are bound to have an impact on how they take up the supervisory role with their students. This raises the question: "to what extent has the role of an academic research supervisor become contaminated, thus resulting in a perverse, poisonous role?" It is therefore recommended that research be conducted into the role in a given 
organisational system. "De-toxification" implies an exploration of the dynamic roots of the academic supervisor role from a systemic perspective. Failure to do so could continue to have an adverse impact on the well-being of academic research supervisors and the success of their students

\section{ACKNOWLEDGEMENTS}

I would like to thank my critical readers for their meaningful comments on the preliminary draft of this article.

\section{FUNDING}

This research received no specific grant from any funding agency in the public, commercial or not-for-profit sectors.

\section{REFERENCES}

Adler, P. A. and P. Adler. 2005. "The identity career of the graduate student: Professional socialisation to academic sociology." The American Sociologist 36(2): 11-17.

Akala, B. and J. Backhouse. 2015. “'They can't even agree!' Student conversations about their supervisors in constructing understanding of the PhD." South African Journal of Higher Education 29(4).

Alvesson, M. and K. Sköldberg. 2010. Reflexive methodology: New vistas for qualitative research. London: Sage.

Alvesson, M. and H. Willmott. 2002. "Identity regulation as organizational control: Producing the appropriate individual." Journal of Management Studies 39: 619-644.

Arinto, P. B. 2016. "Issues and challenges in open and distance e-learning: Perspectives from the Philippines." International Review of Research in Open and Distributed Learning 17(2). http://www.irrodl.org/index.php/irrodl/article/view/1393.

Barnard, A. and A-P. Flotman. 2020. "Coping dynamics of consulting psychology doctorate students transitioning a professional role identity: A systems psychodynamic perspective." International Journal of Environmental Research and Public Health 17(1): 5492-5509.

Bastalich, W. 2015. "Content and context in knowledge production: A critical review of doctoral supervision literature." Studies in Higher Education 42(7): 1145-1157.

Braun, D. and D. Clarke. 2006. "Using thematic analysis in psychology." Qualitative Research in Psychology 3(2): 77-101.

Brunning, H. 2014. "Power and vulnerability." Organisational and Social Dynamics 16(2): 259-279.

Campbell, D. 2000. The socially constructed organization. London: Karnac.

Campbell, D. and M. Groenbaek. 2006. Taking positions in the organization. London: Karnac.

Churchill, S. D. 2018. "Explorations in teaching the phenomenological method: Challenging psychology students to 'grasp at meaning' in human science research." Qualitative Psychology 5(2): 207-220.

Chikte, U. M. E. and J. A. Chabilall. 2016. "Exploration of supervisors and student experiences during master's students in a health science faculty." South African Journal of Higher Education 30(1): 57-79. http://dx:doi.org/10.20853/30-1-559.

Cilliers, F. 2018. "The systems psychodynamic role identity of academic research supervisors." South 
African Journal of Higher Education 31(1): 29-49.

Cilliers, F. and L. Terblanche. 2010. "The systems psychodynamic leadership coaching experiences of nursing managers." Health SA Gesondheid 15(1): Art \#457, 9 pages. https://doi.org/10.4102/ hsag.v15i1.457.

Clarke, S. and P. Hoggett. 2009. Research beneath the surface: Psycho-social research methods in practice. London: Karnac.

Clarke, S., H. Hahn and P. Hoggett. 2008. Object relations and social relations. London: Karnac.

Collini, S. 2017. Speaking of universities. New York: Verso.

Costa, K. A. 2019. "Systematic review of challenges in research supervision at South African universities." Preprints 2018120305. http://dx:doi:10.20944/preprints201812.0305.v1.

Council on Higher Education. 2016. South African higher education reviewed: Two decades of democracy. Pretoria: Council on Higher Education.

Crowther, S., E. Smythe, and D. Spence. 2015. "Kairos time at the moment of birth." Midwifery 31: 451-457. https://doi:10.1016/j.midw.2014.11.005.

Czander, W. M. 1993. The psychodynamics of work and organizations. Guilford, New York.

De Board, R. 2014. The psychoanalysis of organisations: A psychoanalytic approach to behaviour in groups and organisations. London: Routledge.

Emilsson, U. M. and E. Johnsson. 2007. "Supervision of supervisors: On developing supervision in postgraduate education." Higher Education Research and Development 26(2): 163-179. https://doi:10.1080/07294360701310797.

Fowlie, H. and C. Sills. 2011. Relational transactional analysis: Principles in practice. London: Karnac.

Fraher, A. 2004. A history of group study and psychodynamic organisations. London: Free Association.

Garrison, R. 2009. "Implications of online learning for the conceptual development and practice of distance education." Journal of Distance Education/Revue de L' education a Distance 23(2): 93104.

Gordon, P. J. 2003. "Advising to avoid or to cope with dissertation hang-ups." Academy of Management Learning and Education 2(2): 181-187.

Govender, K. K. and S. Ramroop. 2013. "The relationship between the postgraduate research climate, role clarity and research service quality: Exploring the supervisors' and students' perceptions." South African Journal of Higher Education 27(1): 94-109

Halse, C. and P. Bansel. 2012. "The learning alliance: Ethics in doctoral supervision." Oxford Review of Education 38(4): 377-392. https://doi:10.1080/03054985.2012.706219.

Halton, W. 2003. "Some unconscious aspects of organisational life." In Group process consultation reader, ed. F. Cilliers and P. Koortzen, 150-156. Pretoria: University of South Africa.

Hoggett, P. 2013. "Governance and social anxieties." Organisational \& Social Dynamics 13(1): 69-79.

Hollway, W. 2013. "Locating unconscious, societal-collective processes in psycho-social research." Organisational \& Social Dynamics 13(1): 22-40.

Jansen, J. 2017. As by fire: The end of the South African university. Cape Town: Tafelberg.

Jemstedt, A. 2000. "Potential space: The place of encounter between inner and outer reality." International Forum Psychoanalysis 9(1): 124-131.

Kam, B. H. 1997. "Style and quality in research supervision: The supervisor dependency focus." Higher Education 34(1): 81-103.

Klein, M. 1997. Envy and gratitude and other works 1946-1963. Vintage, Reading: PA.

Kreiner, G. E., C. E. Hollensbe, and M. L. Sheep. 2006. "Where is the 'Me' among the 'We'? Identity work and the search for optimal balance." Academy of Management Journal 49(1): 1031-1057.

Lee, A. 2012. Successful research supervision: Advising students doing research. London: Routledge. 
Leibowitz, B. 2017. "Cognitive justice and the higher education curriculum." Journal of Education 68(1): 93-112.

Long, S. 2006. "Role biography." In Coaching in Depth: The organisational role analysis approach, ed. J. Newton, S. Long and B. Sievers. London: Karnac.

Long, S. 2008. The Perverse Organisation and its deadly sins. London: Karnac.

Long, S. 2013. Socioanalytic methods: Discovering the hidden in organisations and social systems. London: Karnac.

Long, S. 2018. Transforming experience in organisations: A framework for organisational research and consultancy. London: Routledge.

Lucey, H. and C. Rogers. 2007. "Power and the unconscious in doctoral-supervisor relationships." In Institutional is political, ed. V. Gillies, 16-36. London: Palgrave Macmillan.

Maclaran, P. and M. Catterall. 2002. "Analysing qualitative data: Computer software and the market research practitioner." Qualitative Market Research 5(1): 28-39.

Madurai, M. 2017. "The systems psychodynamic role analysis of the $21^{\text {st }}$ century leader." Unpublished $\mathrm{PhD}$ Thesis. University of South Africa.

Magano, D. 2013. "The lament of a female postgraduate $\mathrm{PhD}$ student at a South African university: An academic wellness perspective." International Journal of Higher Education 2(20): 211-221.

Marginson, S. 2016. "Public/private in higher education: A synthesis of economic and political approaches." Studies in Higher Education 2(20): 1-16.

Marcketti, S. B., M. W. Mhango and M. B. Gregoire. 2006. "The experiences of African graduate students in a college of human sciences." Journal of Family and Consumer Sciences Education 24(1): 63-72.

May, M.S. 2018. "Shame! A systems psychodynamic perspective." SA Journal of Industrial Psychology 38(2): 138-146.

Maxwell, T. W. and R. Smyth. 2009. "Theorising about higher degree research supervision: A tripartite view." Higher Education Research and Development 59(2): 407-422.

McAlpine, L. and J. Weiss. 2000. "Mostly true confessions: Joint meaning-making about the thesis journey." Canadian Journal of Higher Education 30(1): 1-26.

Motala, E., S. Vally, and R. Maharajh. 2018. "Education, the state and class inequality: The case for free higher education in South Africa." In New South African Review 6, ed. D. Pillay, G. Khadiagala, R. Southall, and S. Mosoetsa. Johannesburg: Wits University Press.

Nagel, C. 2020. Psychodynamic coaching: Distinctive features. New York: Routledge.

Obholzer, A. and V. Z. Roberts. 1994. The unconscious at work. London: Routledge.

O'Hara, S. 2018. "Autoethnography: The science of writing your lived experience." Health Environments Research 11(4): 14-17.

Petriglieri, G. 2020. " $\mathrm{F}^{* *} \mathrm{k}$ science!? An invitation to humanize organization theory." Organisation Theory 1(1): 1-18.

Petriglieri, G. and J. L. Petrilieri. 2010. "Identity workspaces: The case of business schools." Academy of Management Learning and Education 9(1): 44-60.

Petriglieri, G., J. L. Petrilieri, and J. D. Wood. 2018. "Fast tracks and inner journeys: Crafting portable selves for contemporary careers." Administrative Science Quarterly 63: 479-525.

Pithouse-Morgan, K., L. Masinga, I. Naicker, T. Hlao, and D. Pillay. 2016. “'Sink or swim?': Learning from stories of becoming academics within a transforming university terrain." South African Journal of Higher Education 30(1): 224-244. http://dx:doi.org/10.20853/30-1-561.

Sievers, B. 2009. Psychoanalytic studies of organisations. London: Karnac.

Sievers, B. and U. Beumer. 2006. "Organisational role analysis and consultation: The organisation as inner object." In Coaching in depth, ed. S. Long, J. Newton, and B. Sievers, 65-82. Routledge: 
London.

Snow, D. A. and L. Anderson. 1987. "Identity work among the homeless: The verbal construction and avowal of personal identities." American Journal of Sociology 92: 1336-1371.

Sonn, R. 2016. "The challenge for a historically disadvantaged South African university to produce more postgraduate students." South African Journal of Higher Education 30(2): 226-241. http://dx:doi.org/10.20853/30-2-601.

Swartz, R., M. Ivancheva, L. Czerniewicz, and N. P. Morris. 2018. "Between a rock and a hard place: Dilemmas regarding the purpose of public universities in South Africa." Higher Education 77: 567-583.

Todd, M. J., K. Smith, and P. Bannister. 2006. "Supervising a social science undergraduate dissertation: Staff experiences and perceptions." Teaching in Higher Education 11(2): 161-173.

Tohidian, I. and H. Rahimian. 2019. "Bringing Morgan's metaphors in organization contexts: An essay review." Cogent Business and Management 6(1): 15-20.

Van Biljon, J. A. and M. R. De Villiers. 2013. "Multiplicity in supervision models: The supervisor's perspective." South African Journal of Higher Education 27(6): 226-241.

Van Laren L., K. Pithouse-Morgan, T. Chisanga, L. Harrison, T. Meyiwa, N. Muthukrishna, I. Naicker and L. Singh. 2014. "“Walking our talk': Exploring supervision of postgraduate self-study research through metaphor drawing." South African Journal of Higher Education 28(2): 211-221.

Van Manen, M. 2014. Phenomenology of practice: Meaning-giving methods in phenomenological research and writing. Walnut Creek, CA: Left Coast Press.

Van Wyk, N. C., M. Coetzee, Y. Havenga, and T. Heyns. 2015. "Appreciation of the research supervisory relationship by postgraduate nursing students." International Nursing Review 63(1): 26-32. https://doi.org/10.1111/inr.12202.

Victor, K. and A. Barnard. 2016. "Slaughtering for a living: A hermeneutic phenomenological perspective on the well-being of slaughterhouse employees." International Journal of Qualitative Studies on Health and Well-being 11(1): 130-166. https://doi:10.3402/qhw.v11.30266.

Vince, R. 2018. "Institutional illogics: The unconscious and institutional analysis." Organisation Studies 40: 953-973.

Waghid, Y. 2015. Dancing with doctoral encounters. Democratic education in motion. Stellenbosch: Sun Press.

Winnicott, D. W. 1975. Transitional objects and transitional phenomena. London: Hogarth Press.

Yousuf, R., M. D. Mushtahid, M. D. Salam, N. Islam, and A. Salam. 2019. "Research supervision: Issues and perspectives for its success." International Medical Journal 26(4): 335-337. 